\title{
A Simultaneous X-ray Diffraction-Differential Scanning Calorimetry Study into the Phase Transitions of Mefenamic Acid
}

Authors

\section{Yuying Pang ${ }^{\mathrm{a}}$, Asma Buanz ${ }^{\mathrm{a}}$, Richard Telford ${ }^{\mathrm{b}}$, Oxana V. Magdysyuk, ${ }^{\mathrm{c}}$ Simon Gaisford ${ }^{\mathrm{a}}$ and}

Gareth R. Williams* ${ }^{\text {a* }}$

aSchool of Pharmacy, University College London, 29-39 Brunswick Square, London, WC1N 1AX,

United Kingdom

${ }^{\mathrm{b}}$ School of Chemistry and Biosciences, University of Bradford, Richmond Road, Bradford, BD7 1DP, United Kingdom

${ }^{c}$ Diamond Light Source, Harwell Science and Innovation Campus, Didcot, Oxfordshire, OX11 0DE, United Kingdom

Correspondence email: g.williams@ucl.ac.uk

Synopsis The phase transitions of mefenamic acid (MA) have been studied by synchrotron X-ray powder diffraction combined with differential scanning calorimetry. A direct transition from form I to forms II and III was noted, with the possibility of a new and as yet unidentified form observed during heating.

Abstract In this study, the polymorphic transitions of mefenamic acid (MA) were studied by synchrotron X-ray powder diffraction combined with differential scanning calorimetry (XRD-DSC). The initial material was found to be phase-pure form I. When this was heated, two endotherms were observed by DSC, at 162.72 and $219.55{ }^{\circ} \mathrm{C}$. The former was found to correspond to a solid-solid enantiotropic transition from form I to a mixture of form II and III. The latter is the melting point of form II. As form I is heated, significantly greater unit cell expansion is seen in the a direction than in b and $\mathrm{c}$, which can be explained because there are stronger intermolecular interactions in the bc plane. Refinements of the MA diffraction models against the patterns collected during heating revealed that at $175{ }^{\circ} \mathrm{C}$ there exists a mixture of forms I, II and III, while only forms II and III remain at $205{ }^{\circ} \mathrm{C}$. However, reflections are observed at both temperatures which cannot be fitted with the known forms of MA. It is hypothesised that a new form of MA is formed upon heating. The stability of MA after the enantiotropic transition temperature is form II > III > I, which differs from the previously reported II > I > III.

Keywords: Synchrotron X-ray diffraction; differential scanning calorimetry; hyphenated techniques; mefenamic acid; polymorphic transition 


\section{Introduction}

Most drugs are administered orally as solid materials. These must then dissolve in an aqueous environment (e.g. in the stomach and small intestine) to make an effective medicine - this is required for the drug to be absorbed by the body (Aulton \& Taylor, 2013). However, up to $70 \%$ of new drug candidates have poor aqueous solubility and do not dissolve easily (Gaisford, 2013; Kawabata et al., 2011; Morissette et al., 2004). Accessing and stabilising more soluble solid forms of a drug can alleviate these problems, but systematic approaches to doing this remain highly elusive.

Mefenamic acid (MA, 2-[(2,3-dimethylphenyl)amino]benzoic acid) belongs to the non-steroidal antiinflammatory class of drug (NSAIDs). It potently inhibits prostaglandin synthetase, primarily acting as an analgesic and anti-inflammatory agent (Cesur \& Gokbel, 2008; Kato et al., 2006). MA belongs to Class II of the Biopharmaceutical Classification System, having low solubility and high permeability, which hampers its use in the clinic (SeethaLekshmi \& Guru Row, 2012). In addition, its high hygroscopicity and tendency to adhere to surfaces cause great problems during granulation and tabletting (Otsuka, 2004). Therefore, extensive efforts have been made to alter MA's solubility and physical properties, for instance through crystal modification. To date, three polymorphs of MA have been reported: the crystal structures are given in Figure 1, and unit cell parameters are listed in Table 1. In all three systems the MA molecules pack as dimers and the dominant intermolecular forces in the structures are hydrogen bonds between the hydrogen on $\mathrm{O} 2$ of one molecule and $\mathrm{O} 1$ on the adjacent molecule $(\mathrm{O} 1 \cdots \mathrm{H}-\mathrm{O} 2 ; \sim 1.68 \AA$ ) . In forms I and III, the dimer is further stabilised through $\pi \cdots \mathrm{H}-\mathrm{C} 3$ interactions, while in form II, $\pi \cdots \mathrm{H}-\mathrm{C} 4, \pi \cdots \mathrm{H}-\mathrm{C} 5$ and $\pi \cdots \pi$ interactions support the dimer units. The phenyl ring carboxylic group and bridging amino group are coplanar, stabilised by an intramolecular $\mathrm{O} 1 \cdots \mathrm{H}-\mathrm{N} 1$ hydrogen bond (Abbas et al., 2017).

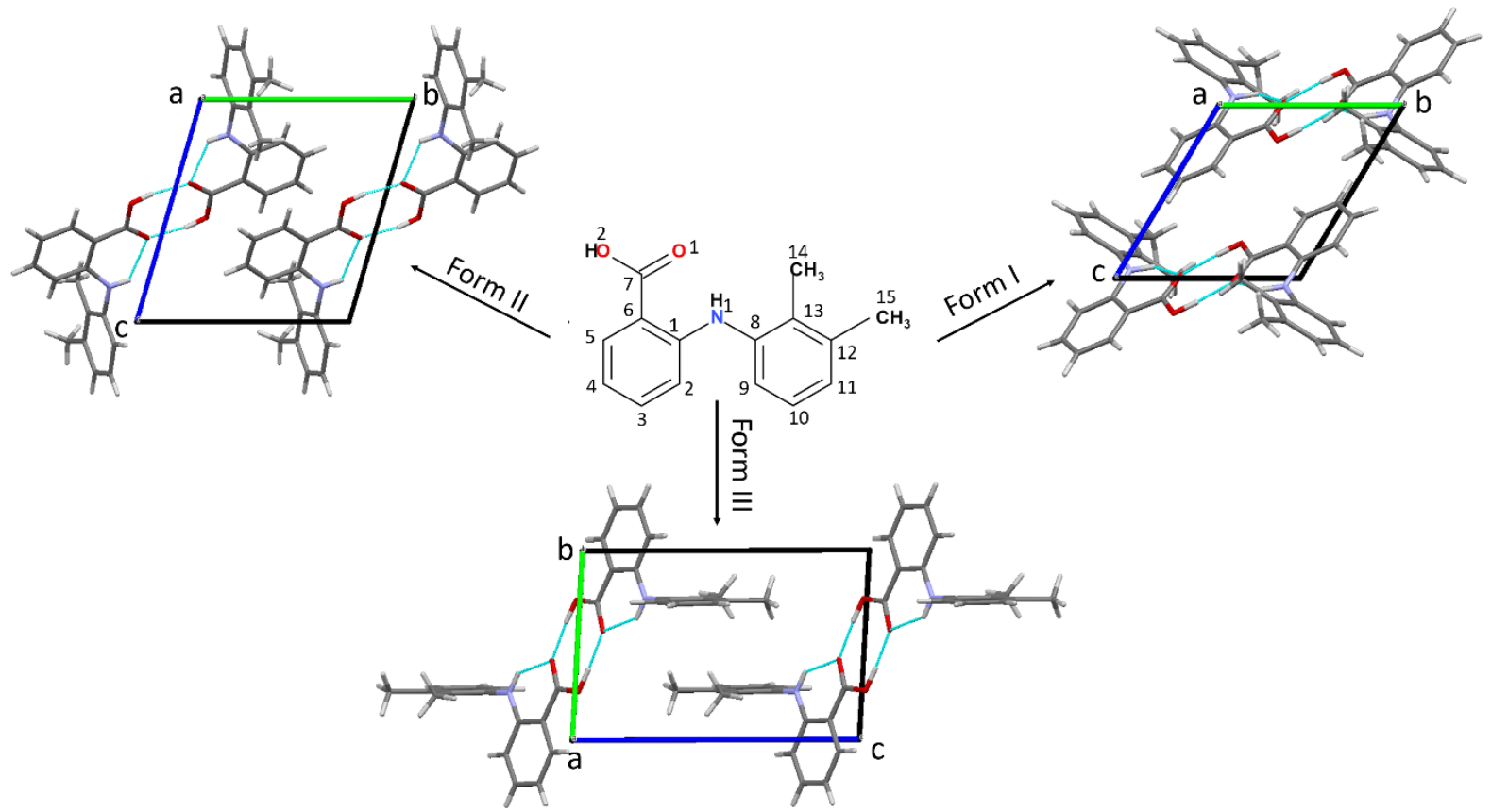




\section{Figure 1}

The molecular packing of MA forms I, II and III, viewed down the a-axis. Disorder present in the structure of form II is omitted for clarity.

\section{Table 1}

Crystallographic data for MA forms I, II and III.

\begin{tabular}{|c|c|c|c|}
\hline Form & $\mathbf{I}^{\mathbf{a}}$ & II & III \\
\hline CSD ID & XYANAC & XYANAC02 & XYANAC03 \\
\hline $\begin{array}{l}\text { Crystal } \\
\text { system }\end{array}$ & Triclinic & Triclinic & Triclinic \\
\hline Space group & P-1 & $\mathrm{P}-1$ & P-1 \\
\hline $\begin{array}{c}\text { Temperature } \\
\text { (K) }\end{array}$ & 295 & 298 & 298 \\
\hline a/ $\AA$ & 14.556 & $7.7584(5)$ & $7.723(2)$ \\
\hline b/ ̊ & 6.811 & $9.2772(6)$ & $7.934(10)$ \\
\hline c/ $\AA$ & 7.657 & $9.3991(4)$ & $11.232(10)$ \\
\hline$\alpha /^{o}$ & 119.57 & $106.308(5)$ & $83.590(10)$ \\
\hline$\beta /{ }^{\circ}$ & 103.93 & $91.847(4)$ & $80.940(10)$ \\
\hline$\gamma /{ }^{\circ}$ & 91.3 & $101.865(5)$ & $67.510(10)$ \\
\hline $\begin{array}{c}\text { Cell volume } \\
\text { (§) }\end{array}$ & 631.766 & 632.52 & 626.96 \\
\hline $\begin{array}{l}\text { Density } \\
\left(\mathrm{g} / \mathrm{cm}^{\mathbf{3}}\right)\end{array}$ & 1.268 & 1.267 & 1.278 \\
\hline $\mathbf{Z}$ & 2 & 2 & 2 \\
\hline $\mathbf{Z}^{\prime}$ & 1 & 1 & 1 \\
\hline
\end{tabular}

${ }^{\text {a }}$ SUs are not given in the CSD for form I.

MA form I is the commercially available form, and in the lab can be obtained by cooling a supersaturated acetone solution (Kato et al., 2006). Form II is prepared by rapid cooling a supersaturated dimethyl formamide (DMF) solution (Kato et al., 2006; SeethaLekshmi \& Guru Row, 2012) or by slow evaporation of a chloroform solution in low humidity conditions (SeethaLekshmi \& Guru Row, 2012). MA form III was obtained fortuitously during co-crystallisation, and can be prepared by slow evaporation of a MA DMF/methanol solution with adenine present as an additive (SeethaLekshmi \& Guru Row, 2012). MA form II is reported to exhibit a higher solubility than form I in several solvents; however, being metastable it will slowly convert to form I at room temperature (Kato et al., 2006). SeethaLekshmi and Guru Row (2012) determined that the relative stabilities of MA at ambient conditions lie in the order form I > II > III, which changes to form II > I > III at $175^{\circ} \mathrm{C}$ and above. 
In this work a novel method is employed to analyse the phase transitions of MA, combining high energy synchrotron X-ray powder diffraction with differential scanning calorimetry (XRD-DSC) (Figure 2). By using this technique, structural changes can be quantified via the XRD patterns, and phase transitions during heating and cooling observed by DSC. The technique allows for real time characterization, as both XRD and DSC data are obtained simultaneously on the same sample (Clout $e t$ al., 2016). Clout et al. (2016) demonstrated that XRD-DSC experiments can be performed after simply modifying a laboratory DSC instrument by drilling holes through the furnace to allow a synchrotron Xray beam to pass unhindered through the sample pan (Figure 2). The XRD-DSC approach has been applied to study phase transitions in a range of systems including carbamazepine (Clout et al., 2018), paracetamol/lactose blends (Telford et al., 2016), and spray-dried amorphous solid dispersions of olanzapine (Askin et al., 2019). In this work, we make a further advance to the technique by dint of incorporating a controlled cooling facility into the experimental set-up.
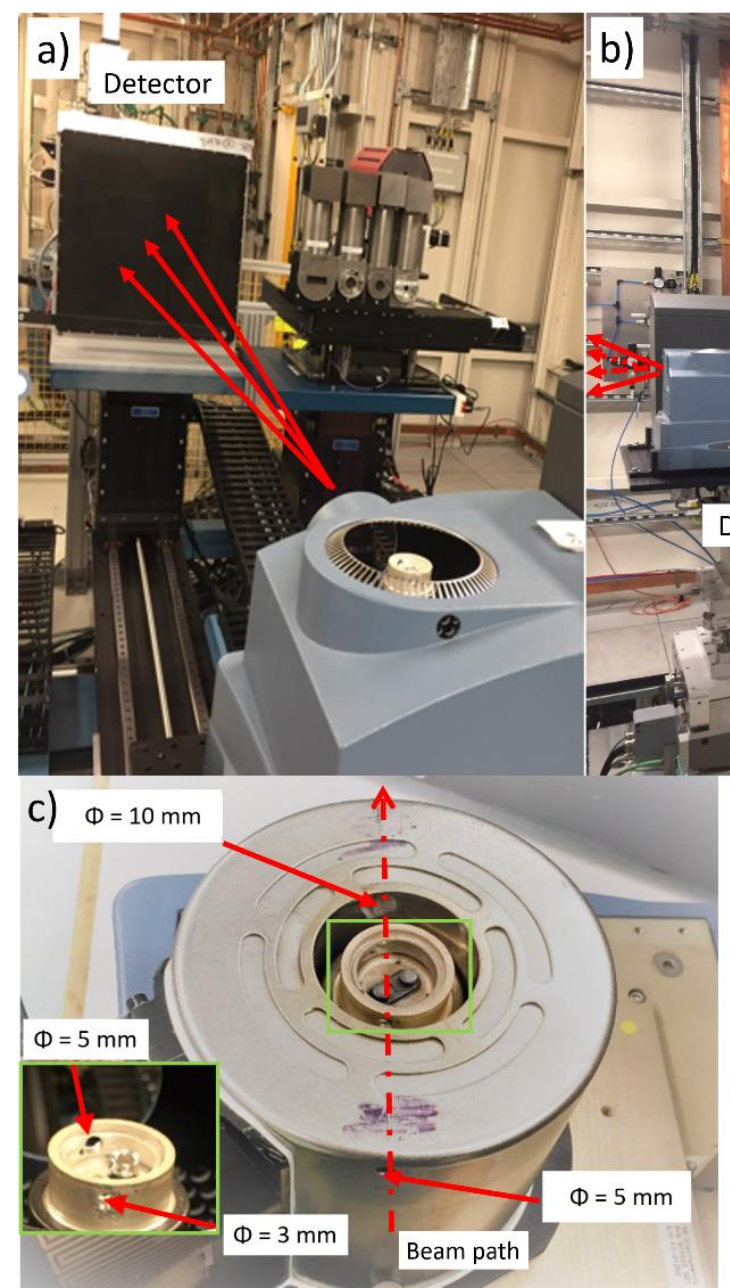

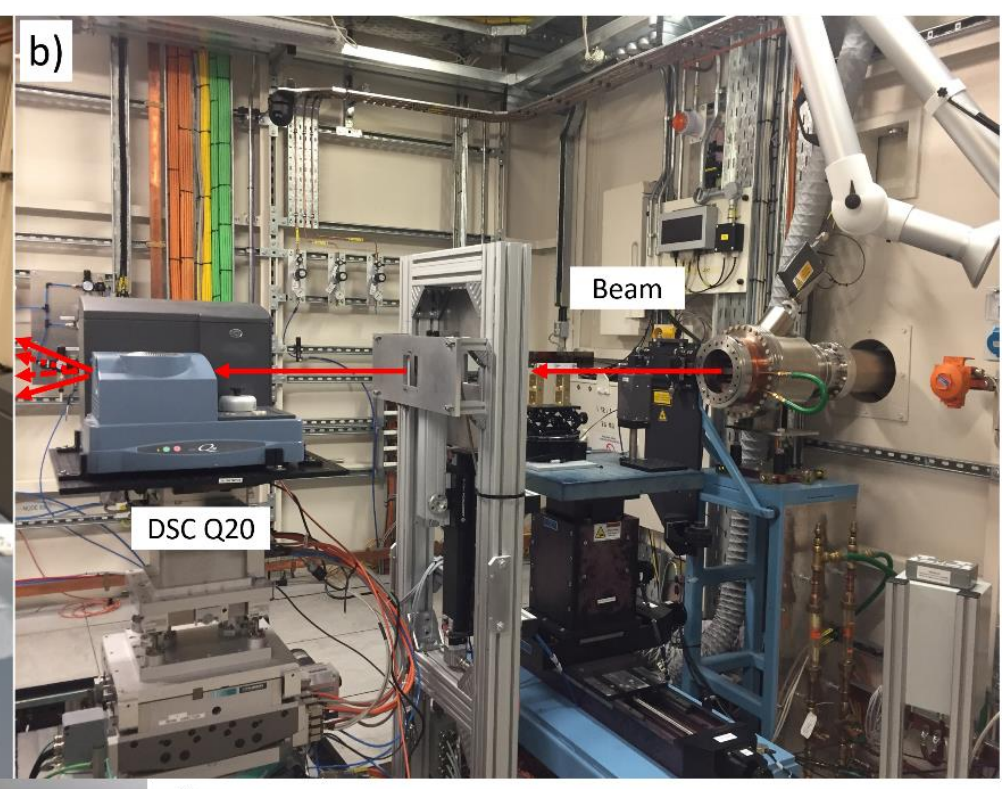

d)

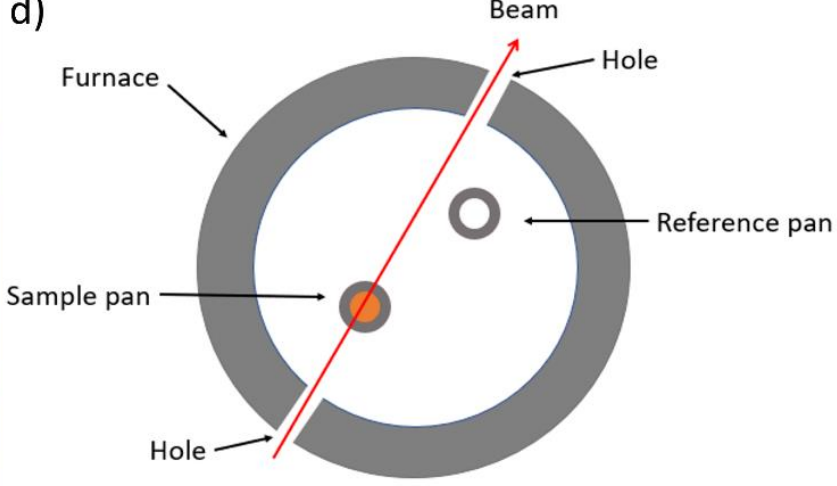

\section{Figure 2}

Images showing the XRD-DSC experimental approach. a) and b) The experimental set up for XRDDSC experiments on Beamline I12 at the Diamond Light Source. The red lines indicate the path of the 
X-ray beam; c) A digital photograph of the modified Q20 DSC (inset: furnace; main image: cooling unit); d) A schematic of the modified DSC furnace for XRD-DSC experiments

\section{Materials and methods}

MA (lot L102034, 98\%) was obtained from Alfa Aesar and used as supplied. Standard laboratory XRD experiments were undertaken on a MiniFlex 600 diffractometer (Rigaku) supplied with $\mathrm{Cu}-\mathrm{K} \alpha$ radiation $(\lambda=0.15418 \mathrm{~nm}, 40 \mathrm{kV}, 15 \mathrm{~mA})$. MA samples were loaded in low volume glass holders and scanned from 5 to $50^{\circ}$ in $0.02^{\circ}$ steps at $2 \%$ min. Nuclear magnetic resonance (NMR) experiments were performed on a Bruker Avance $400 \mathrm{MHz}$ spectrometer, with DMSO-d6 as the solvent.

Thermal analysis was carried out using a DSC (Q2000 calorimeter, TA Instruments). Nitrogen was used as the purge gas, with a flow rate of $50 \mathrm{~mL} / \mathrm{min}$. Three DSC methods were employed: in the first method, the sample was heated from 20 to $240{ }^{\circ} \mathrm{C}$ at $10{ }^{\circ} \mathrm{C} / \mathrm{min}$. In the second method the sample was heated from 20 to $180{ }^{\circ} \mathrm{C}$ at $10{ }^{\circ} \mathrm{C} / \mathrm{min}$, cooled to $0{ }^{\circ} \mathrm{C}$ and then reheated to $240{ }^{\circ} \mathrm{C}$ at the same heating rate. In the third method, MA was heated from 20 to $180^{\circ} \mathrm{C}$ at $100^{\circ} \mathrm{C} / \mathrm{min}$. Thermogravimetric analysis (TGA; Discovery TGA, TA Instruments) was also performed. Samples were heated from room temperature to $300{ }^{\circ} \mathrm{C}$ at $10{ }^{\circ} \mathrm{C} / \mathrm{min}$ under a nitrogen purge at $25 \mathrm{ml} / \mathrm{min}$. All temperatures are reported as onset temperatures. These are preferred because they usually stay unchanged with variations in heating rate or sample preparation method, which might cause broadening of the transition peaks resulting in the shift of peak temperature. The temperatures given for DSC data are thus the temperatures where polymorphic transitions begin, rather than when they are complete.

Simultaneous XRD-DSC experiments were carried out on the Joint Engineering, Environment and Processing Beamline I12 (JEEP) at the Diamond Light Source (Drakopoulos et al., 2015). A Q20 DSC (TA Instruments) fitted with a refrigerated cooling system (RCS) attachment (TA Instruments) was mounted onto the sample stage in the experimental hutch, as depicted in Figure 2a and b. The DSC and RCS had both previously been modified to permit passage of the synchrotron beam. Holes were drilled in the cooler and furnace, with the entry holes being $5 \mathrm{~mm}$ (RCS) and $3 \mathrm{~mm}$ (furnace) in diameter and the exit holes $10 \mathrm{~mm}$ (RCS) and $5 \mathrm{~mm}$ (furnace) (see Figure 2c). The wavelength of the X-ray beam was monochromated to $0.234 \AA(53.2 \mathrm{keV})$, and the beam diameter was $0.5 \mathrm{~mm}$. The beam is almost parallel at the sample position. A Thales Pixium RF4343 detector was located $1.9 \mathrm{~m}$ behind the sample. The wavelength and sample-detector distance were calibrated with cerium dioxide $\left(\mathrm{CeO}_{2}\right)$ prior to experiments beginning, according to a previously reported calibration procedure (Hart et al, 2013). $\mathrm{CeO}_{2}$ was measured at two distances ( $\mathrm{L}$ and $\mathrm{L}+100 \mathrm{~mm}$ ). Since all the d-spacings of $\mathrm{CeO}_{2}$ are known, the peak positions on the detector plate can be used to calibrate the wavelength and sample-detector distance. This calibration was undertaken using the DAWN Science Workbench (Basham et al., 2015; Filik et al., 2017). The DSC was calibrated with an indium standard.

For XRD-DSC experiments, MA samples of ca. $20 \mathrm{mg}$ were loaded into crimped Tzero aluminium pans with pin-holed hermetic lids. The samples were loaded into the DSC furnace and heated from 20 
${ }^{\circ} \mathrm{C}$ to $240{ }^{\circ} \mathrm{C}$ at $10{ }^{\circ} \mathrm{C} / \mathrm{min}$, with nitrogen used as a purge gas. DSC data were recorded using the TA Advantage software and analysed in the TA Universal Analysis software. The Diamond Generic Data Acquisition (GDA) software was employed to collect diffraction patterns for $5 \mathrm{~s}$, with a $1 \mathrm{~s}$ pause between each scan. This permits a diffraction pattern to be collected for every $1{ }^{\circ} \mathrm{C}$ increase in sample temperature.

XRD data were analysed as follows. The DAWN Science Workbench was used to mask and convert the 2D Pixium datasets into 1D diffraction patterns by azimuthal integration (Basham et al., 2015; Filik et al., 2017). The raw XRD data were then plotted as a function of temperature in contour plots using OriginPro 2017. TOPAS-Academic V5 was employed to analyse selected patterns with the Rietveld method (Rietveld, 1967; Rietveld, 1969) implemented within the software, in order to obtain realistic values for the unit cell parameters at elevated temperatures (Coelho et al., 2012). Since synchrotron Xray data were collected as $2 \mathrm{D}$ images, no zero point needed to be refined. Linear interpolation and subtraction were used for background refinement, and peak shapes were refined with pseudo-Voigt functions. For lattice parameters, least-squares fitting was employed and the intensities of calculated reflections iterated to best fit the observed data (McCusker et al., 1999). If an XRD pattern contained more than one phase, the peak shapes for each phase were set to be the same and the phase fractions were refined.

\section{Results}

\subsection{Physical properties of MA}

MA was first characterised by XRD, TGA and DSC. The XRD profile confirms the material supplied to be form I (Supporting Information, Figure S1). According to the TGA profile (Figure 3), thermal degradation began at ca. $180^{\circ} \mathrm{C}$. The DSC data for MA form I are also shown in Figure 3. Two endothermic peaks are visible with onsets at 162.72 and $219.55^{\circ} \mathrm{C}$, respectively corresponding to the polymorphic transition from form I to form II and the melting of form II. The DSC and TGA results together suggest that degradation occurs on melting, which has not been noted for MA previously. 


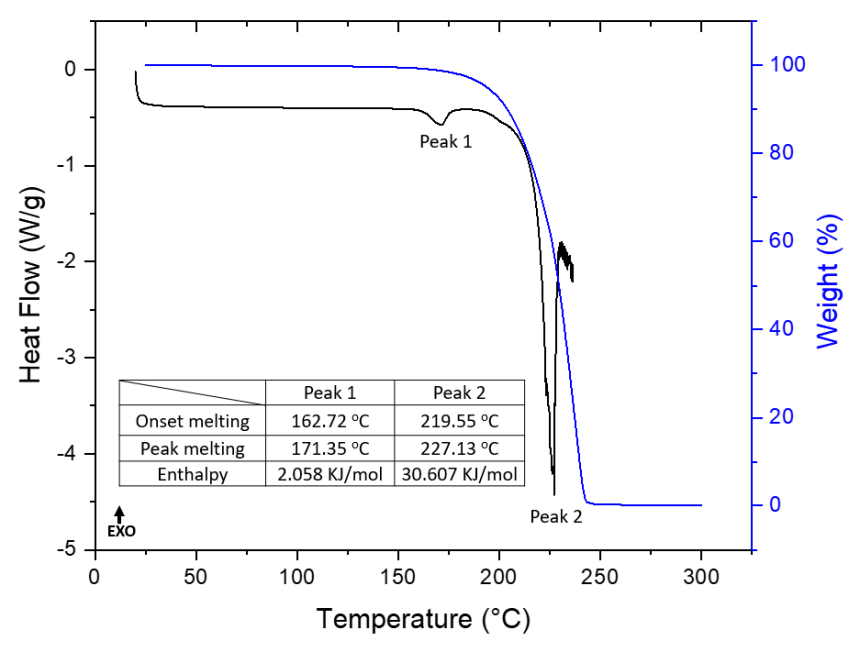

Figure 3

Overlay of the DSC and TGA results obtained on as-supplied MA (the enthalpy of the second endotherm in DSC is not accurate due to the degradation of MA).

Using a DSC heat-cool-heat cycle, MA was heated to a temperature just above the completion of the first endotherm, cooled down to $0{ }^{\circ} \mathrm{C}$, and then reheated to $240{ }^{\circ} \mathrm{C}$ (see Figure 4). The results demonstrated that no recrystallisation happened during the reheating process (the peak at $15{ }^{\circ} \mathrm{C}$ is a baseline shift artefact), and the data obtained during the second heat present only an endothermic peak at $220^{\circ} \mathrm{C}$. This is the melting point of form II according to the literature (SeethaLekshmi \& Guru Row, 2012). These observations indicate that after the first endothermic event, form I has been converted into form II. When increasing the heating rate to $100^{\circ} \mathrm{C} / \mathrm{min}$ (Figure S2), the DSC data show that the first (smaller) endothermic peak shifts to higher temperature, confirming it arises as a result of kinetic rather than thermodynamic events. Hence, the first endothermic transition can be confirmed as the enantiotropic transition from MA form I to form II. 


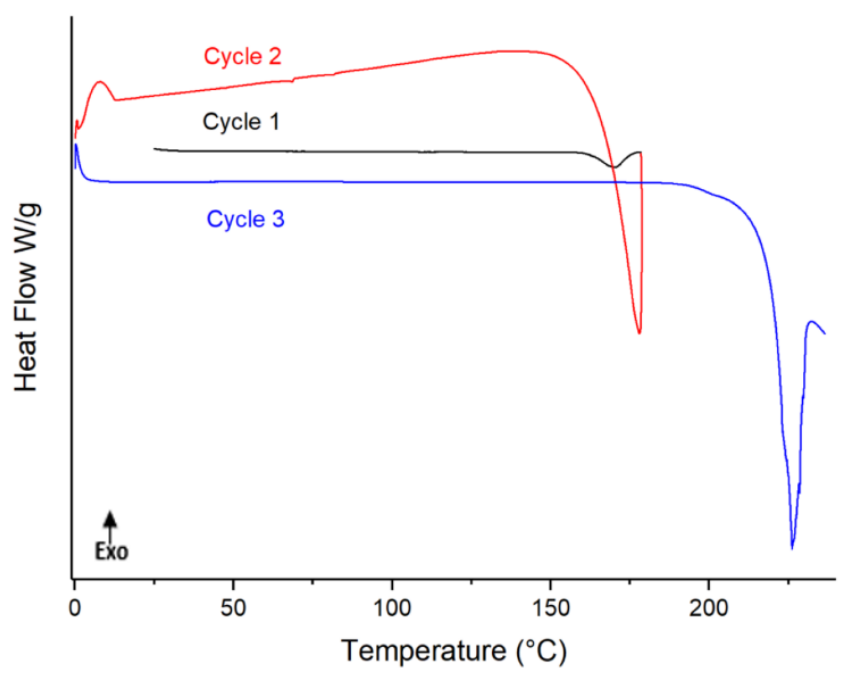

Figure 4

DSC data collected during heat-cool-heat cycles with MA (cycle 1 and cycle 3: heating, cycle 2: cooling).

\subsection{XRD-DSC}

XRD-DSC data for MA can be seen in Figure 5. Data collection began at $25{ }^{\circ} \mathrm{C}$ and no changes in the position of the Bragg reflections are seen until around $160{ }^{\circ} \mathrm{C}$, at which point a second crystalline phase appears. Both the initial and the second crystalline phase coexist from $160{ }^{\circ} \mathrm{C}$ to $179{ }^{\circ} \mathrm{C}$, when the MA is completely converted to the latter. Slight changes in the diffraction pattern are observed between 200 to $220^{\circ} \mathrm{C}$, which may be because MA begins to melt in this temperature range. The DSC trace shows a small endothermic event with an onset at $163.47{ }^{\circ} \mathrm{C}$ coinciding with the polymorphic transition. Following this, there is a much larger endothermic peak at $220^{\circ} \mathrm{C}$. The latter results from the melting of form II, as is evident from the total lack of diffraction intensity above this temperature. 


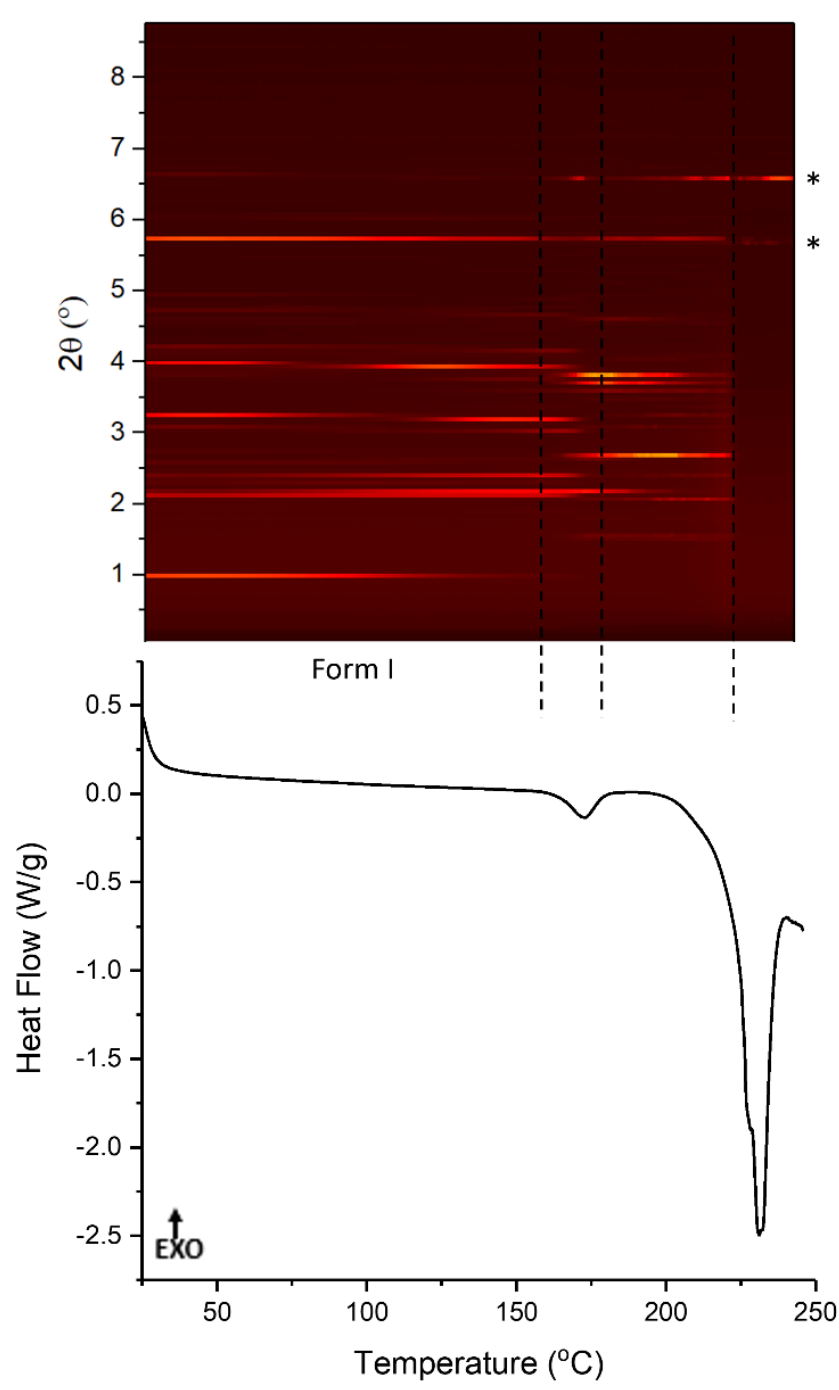

\section{Figure 5}

XRD-DSC data for MA (reflections marked $*$ are a result of the aluminium pan).

Rietveld refinement was carried out using the structure models XYANAC (form I) (McConnell et al., 1976), XYANAC02 (form II) (Lee et al., 2006) and XYANAC03 (form III) (SeethaLekshmi \& Guru Row, 2012) from the Cambridge Structural Database (CSD). The refinement against the initial material at $25^{\circ} \mathrm{C}$ confirms that the sample is phase-pure form I (Figure 6a, Table 2). Rietveld refinement of the pattern recorded at $175{ }^{\circ} \mathrm{C}$, after the profile change, shows that the diffraction pattern contains features corresponding to each of forms I, II and III (Figure 6b, Table 2). At $205^{\circ} \mathrm{C}$, the sample appears to contain form II as well as some reflections from form III (Figure 6c, Table 2). The $\mathrm{R}_{\mathrm{wp}}$ (weight profile R-factor) values of the last two refinements are relatively high, because some of the observed peaks cannot be fitted. 

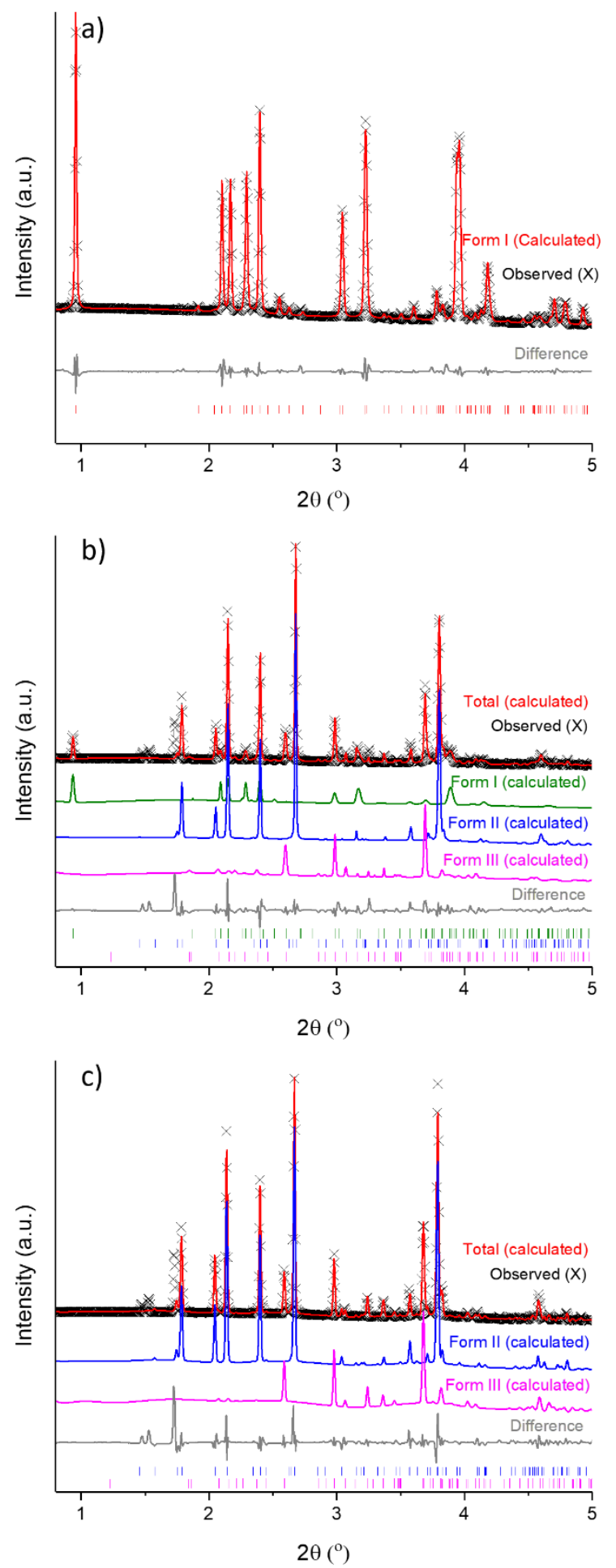

Figure 6

Rietveld refinement against diffraction patterns recorded for MA during heating at $10{ }^{\circ} \mathrm{C} / \mathrm{min}$. Data are shown at a) $25{ }^{\circ} \mathrm{C}$ (tick marks show the position of allowed reflections of MA form I); b) $175{ }^{\circ} \mathrm{C}$ (tick marks show the position of allowed reflections of MA form I (upper), form II (middle) and form III (lower)); c) $205^{\circ} \mathrm{C}$ (tick marks show the position of allowed reflections of MA form II (upper) and form III (lower). 


\section{Table 2}

Refinement parameters for MA form I, form II and form III. The starting models were taken from the CSD (Form I: XYANAC, Form II: XYANAC02, Form III: XYANAC03).

\begin{tabular}{|c|c|c|c|c|c|c|}
\hline $\mathrm{T} /{ }^{\circ} \mathrm{C}$ & 25 & \multicolumn{3}{|c|}{175} & \multicolumn{2}{|c|}{205} \\
\hline & Form I & Form I & Form II & Form III & Form II & Form III \\
\hline $\begin{array}{l}\text { Space } \\
\text { group }\end{array}$ & P-1 & P-1 & P-1 & P-1 & P-1 & P-1 \\
\hline a/ $\AA$ & $14.626(1)$ & $14.802(10)$ & $7.8857(19)$ & $7.9059(51)$ & $7.9115(11)$ & $7.8667(32)$ \\
\hline b/ $\AA$ & $6.8245(3)$ & $6.8607(5)$ & $9.1451(25)$ & $7.8927(24)$ & $9.1585(11)$ & $7.9037(15)$ \\
\hline c/ $\AA$ & $7.6766(4)$ & $7.6694(5)$ & $9.6664(35)$ & $11.098(5)$ & $9.6889(16)$ & 11.131(3) \\
\hline $\boldsymbol{\alpha} /{ }^{\circ}$ & $119.77(0)$ & $120.44(4)$ & $106.83(2)$ & $82.760(40)$ & $106.79(1)$ & $83.218(22)$ \\
\hline$\beta /{ }^{\circ}$ & $104.07(0)$ & $103.28(6)$ & $92.383(18)$ & $79.374(46)$ & $92.599(9)$ & $79.875(21)$ \\
\hline$\gamma /{ }^{\circ}$ & $91.007(5)$ & $91.200(2)$ & $102.69(3)$ & $67.148(37)$ & $102.70(1)$ & $67.417(21)$ \\
\hline $\mathbf{R}_{\mathrm{wp}}$ & 5.0251 & & 13.307 & & & \\
\hline $\begin{array}{l}\text { Phase } \\
\text { fraction }\end{array}$ & $99.0 \%^{\mathrm{b}}$ & $12.2 \%^{\mathrm{c}}$ & $64.0 \%^{c}$ & $23.7 \%^{c}$ & $72.1 \%^{c}$ & $25.9 \%^{\mathrm{c}}$ \\
\hline
\end{tabular}

${ }^{a}$ The representative error of the phase fractions cannot be calculated because of the graininess of the sample. ${ }^{\mathrm{b}}$ The purity of MA is $99 \%$, which results in the phase fraction of MA form I at $25{ }^{\circ} \mathrm{C}$ being

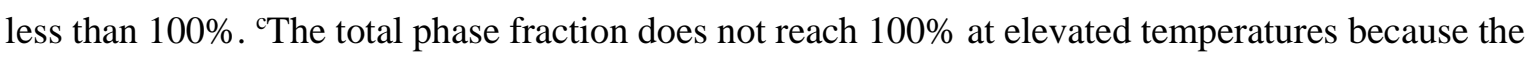
refinement cannot perfectly fit the observed patterns.

A number of the MA form I reflections shift to lower $2 \theta$ angles as the material is heated from 25 to $150{ }^{\circ} \mathrm{C}$ (Figure 5). This is caused by unit cell expansion (Figure 7). The quality of the data collected permitted batch refinements to be performed against all the patterns collected. The unit cell parameters could be extracted from these and plotted as a function of temperature (Figure 7). It is clear that the a dimension expands significantly more than either the $\mathrm{b}$ or $\mathrm{c}$ dimensions; the per degree increase in temperature is 7- and 5-fold greater than that in $\mathrm{b}$ and $\mathrm{c}$ respectively. The dominant intermolecular forces in the structure of form I are hydrogen bonds between the hydrogen on $\mathrm{O} 2$ and $\mathrm{O} 1$ of an adjacent molecule $(\mathrm{O} 1 \cdots \mathrm{H}-\mathrm{O} 2$; Figure 8$)$. These comprise the only intermolecular hydrogen bonding throughout the structure, with an $\mathrm{H} \cdots \mathrm{O}$ distance of $1.68 \AA$ (Abbas et al., 2017). This holds the MA molecules together in dimers, and adjacent dimers are stablised through $\pi \cdots \mathrm{H}-\mathrm{C} 3$ interactions $(2.77$ $\AA$ ). When viewed in the bc plane, it is clear that these interactions stabilise the structure in both the $\mathrm{b}$ and c directions. While the intermolecular H-bond offers some support in the a direction, this is relatively minimal. As a result, the thermal unit cell expansion is more distinct in the a dimension than in $\mathrm{b}$ and $\mathrm{c}$. 


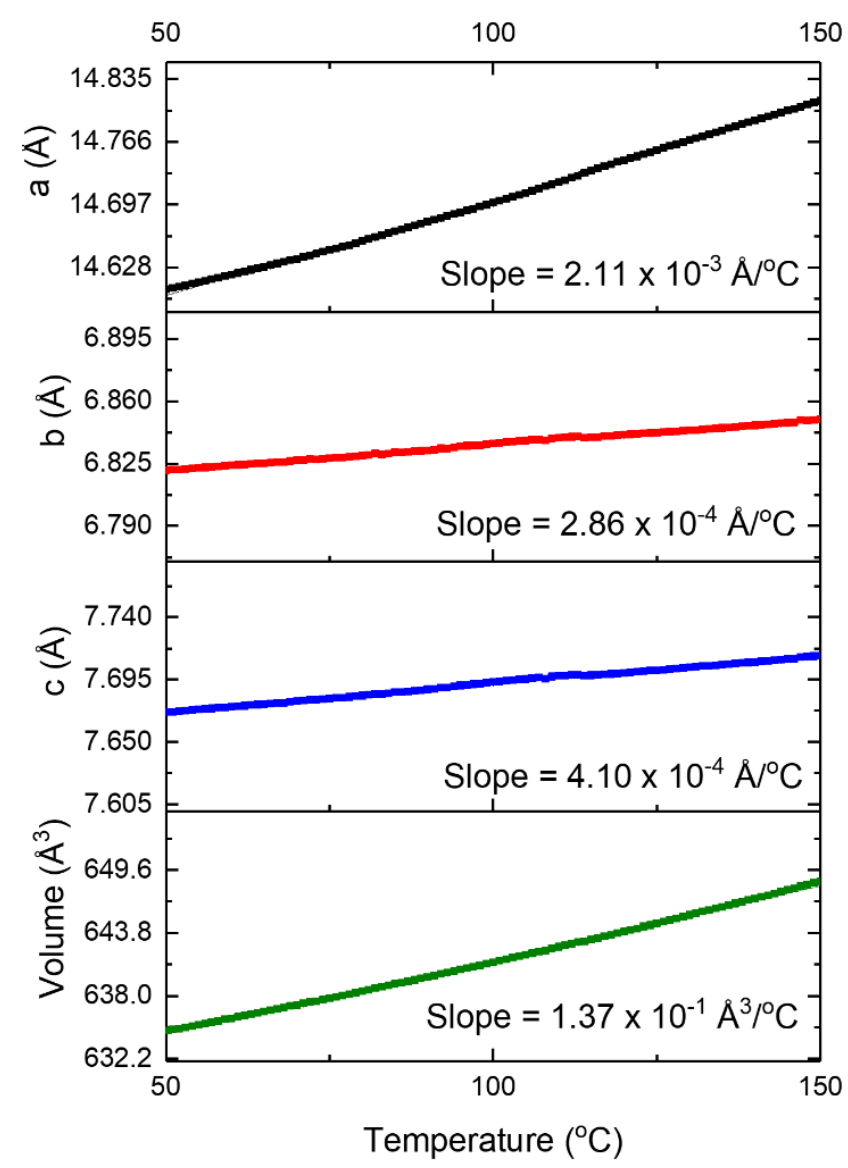

Figure 7

Lattice parameters and unit cell volume as a function of temperature for MA form I.

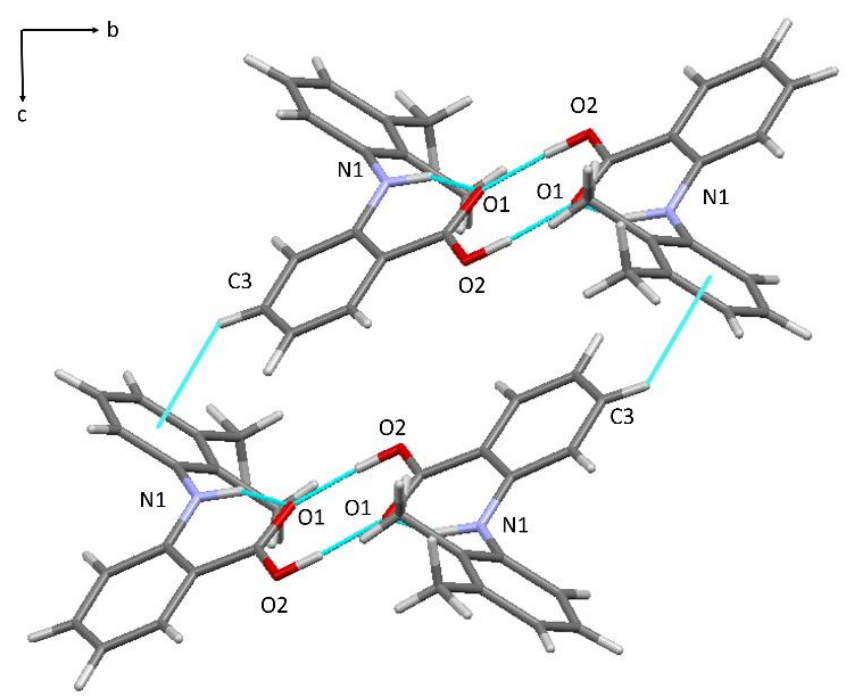

Figure 8

Molecular interactions in the bc plane of MA form I, showing $\mathrm{O} \cdots \mathrm{H}-\mathrm{O}$ intermolecular bonding, $\mathrm{N} \cdots \mathrm{H}-\mathrm{O}$ intramolecular bonding and $\pi \cdots \mathrm{H}-\mathrm{C}$ interactions. 
The integrated total diffraction intensity for each pattern as a function of temperature is plotted in Figure 9. At about $150{ }^{\circ} \mathrm{C}$ the amount of form I begins to decrease, and rapid growth of form II and III is seen. This suggests that form I transforms to forms II and III during the first endothermic peak. The rate of change is almost linear from $150{ }^{\circ} \mathrm{C}$ until around $175^{\circ} \mathrm{C}$, at which point there is no more form I present. The trend line of the most linear part of two curves was analysed (from 169 to $174{ }^{\circ} \mathrm{C}$ ) and a decline in form I of $-5.41{ }^{\circ} \mathrm{C}^{-1}$, and growth of form II/III at $6.43{ }^{\circ} \mathrm{C}^{-1}$ was seen. The similarity between these two numbers indicates the conversion is a direct transition between the polymorphs. The integrated data were converted to phase fractions and plotted as a function of temperature (Figure 9, inset). The two curves cross at around half of the maximum quantity of either of the two phases, indicating that the crystal structure does not transit via a complete melt of the sample, but rather there is a solid-solid phase transition. Overall, the data suggest that the small endothermic peak at $163.47^{\circ} \mathrm{C}$ is likely to be a solid-solid enantiotropic transition from MA form I to forms II and III. After the transition point, the stability of the MA polymorphs lies in the order form II > III > I. This differs to that previously reported series, which found II > I > III (SeethaLekshmi \& Guru Row, 2012). The reason behind this difference is not clear, but SeethaLekshmi found that the difference in energy between form I and III is small at elevated temperatures; hence, it might be that the small changes in sample environment and experimental conditions between our two studies are enough to cause the stability order to alter.

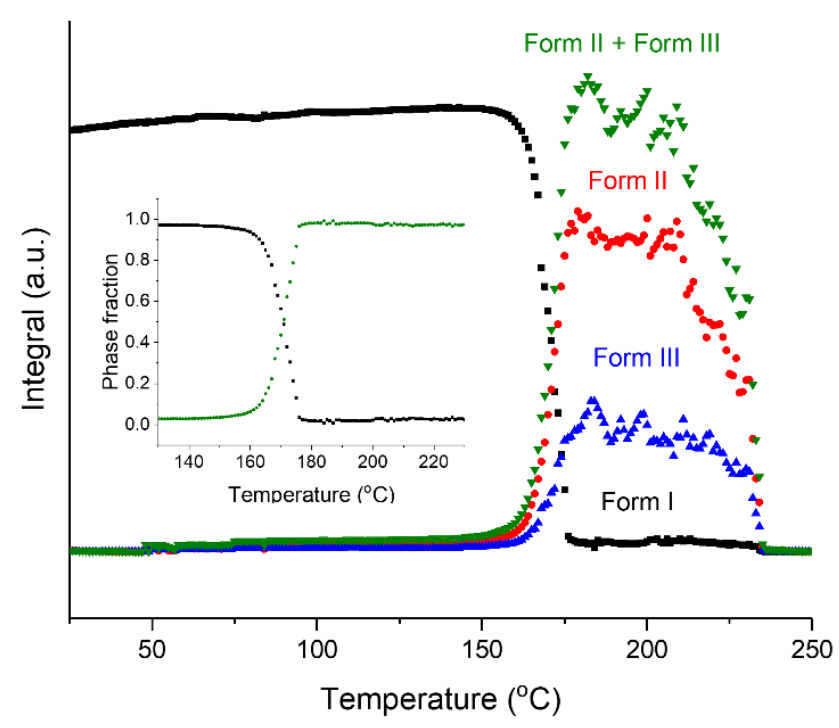

Figure 9

Plot of integrated total diffraction intensity for MA form I, II and III as a function of temperature, with inset plot of phase fraction as a function of temperature. 
MA has three reported polymorphic forms, but the patterns collected at 175 and $205^{\circ} \mathrm{C}$ cannot be perfectly fitted with the known polymorphs. Looking at the data from $205{ }^{\circ} \mathrm{C}$ (Figure 6c), form II accounts for most reflections in the observed pattern, but there are unmatched peaks at 1.47, 1.53, 1.72, 2.58, 2.97 and $3.67^{\circ}$. The form III fit is rather poor, but form III does match some observed reflections which cannot be attributed to form II $\left(2.58,2.97\right.$ and $\left.3.67^{\circ}\right)$. Additional reflections at $1.47,1.53$ and $1.72^{\circ}$ cannot be matched with any of form I, II or III, however. We hypothesised that these could correspond either to degradation products, or to a new polymorph of MA. To investigate the former, MA samples were heated to 175 or $205^{\circ} \mathrm{C}$ following the same heating protocol as for XRD-DSC, cooled to room temperature, and analysed by ${ }^{1} \mathrm{H}$ NMR (Figure S3). The resonances observed in the NMR spectra before and after heating are identical. Thus, although degradation does occur upon heating (see Figure 3), the products of this process must be volatile and cannot account for the additional reflections.

Since degradation is ruled out, the additional reflections must arise from a new polymorph of MA. In an attempt identify this, predicted crystal structures were explored (Case et al., 2018). None of the lowenergy structures provide a good match to the unassigned reflections (Figure S4). It thus appears that an as-yet unknown polymorph of MA was generated during heating. This is highly unstable: when MA is heated to 175 or $205^{\circ} \mathrm{C}$ in the DSC, cooled to room temperature, and analysed by XRD, the patterns obtained match perfectly with form II (Figure S5). The new polymorph therefore quickly converts to form II when the temperature is reduced.

\section{Conclusions}

Combined synchrotron X-ray powder diffraction - differential scanning calorimetry (XRD-DSC) experiments undertaken in this work permitted new insight into the polymorphic transitions of mefenamic acid (MA) to be obtained. When commercially sourced MA form I was heated, two endotherms were observed, at 162.72 and $219.55{ }^{\circ} \mathrm{C}$. The former corresponds to an enantiotropic transition between forms I and II/III, while the latter is the melting of form II. As form I is heated, the unit cell expands, and we observe significantly greater unit cell growth in a than in $b$ and $c$. This is a result of the bc plane being supported by H-bonding. The conversion between form I and II/III appears to occur via a solid-solid pathway, with no wholesale melting observed. At temperatures above the enantiotropic transition point, the diffraction patterns contain reflections which cannot be matched with any of the known forms of MA, suggesting the existence of an as-yet unknown polymorph.

Acknowledgements We thank Prof Sally Price and Dr Louise Price for providing the computationally predicted MA crystal structures, Diamond Light Source for access to Beamline I12 under experiment EE 18720-1, the EPSRC for funding Dr Asma Buanz (EP/K039229/1), and TA Instruments Ltd for donation of the DSC equipment. 


\section{References}

Abbas, N., Oswald, I. D. H. \& Pulham, C. R. (2017). Pharmaceutics 9(2), 6.

Askin, S., Cockcroft, J. K., Price, L. S., Gonçalves, A. D., Zhao, M., Tocher, D. A., Williams, G. R., Gaisford, S. \& Craig, D. Q. M. (2019). Cryst. Growth Des. 19, 1528-7483.

Aulton, M. E. \& Taylor, K. (2013). Aulton`s Pharmaceutics: The Design and Manufacture of Medicines. Churchill Livingstone.

Basham, M., Filik, J., Wharmby, M. T., Chang, P. C. Y., El Kassaby, B., Gerring, M., Aishima, J., Levik, K., Pulford, B. C. A., Sikharulidze, I., Sneddon, D., Webber, M., Dhesi, S. S., Maccherozzi, F., Svensson, O., Brockhauser, S., Náray, G. \& Ashton, A. W. (2015). J. Synchrotron Rad. 22, 853-858.

Case, D. H., Srirambhatla, V. K., Guo, R., Watson, R. E., Price, L. S., Polyzois, H., Cockcroft, J. K., Florence, A. J., Tocher, D. A. \& Price, S. L. (2018). Cryst. Growth De. 18, 5322-5331.

Cesur, S. \& Gokbel, S. (2008). Cryst. Res. Technol. 43, 720-728.

Clout, A., Buanz, A. B., Prior, T. J., Reinhard, C., Wu, Y., O'Hare, D., Williams, G. R. \& Gaisford, S. (2016). Anal. Chem. 88, 10111-10117.

Clout, A. E., Buanz, A. B. M., Gaisford, S. \& Williams, G. R. (2018). Chem.: Eur. J. 24, 1357313581.

Coelho, A. A., Evans, J., Evans, I., Kern, A. \& Parsons, S. (2012). Powder Diffr. 26, S22-S25.

Drakopoulos, M.; Connolley, Th.; Reinhard, C.; Atwood, R.; Magdysyuk, O.; Vo, N.; Hart, M.;

Connor, L.; Humphreys, B.; Howell, G.; Davies, S.; Hill, T.; Wilkin, G.; Pedersen, U.; Foster, A.; De Maio, N.; Basham, M.; Yuan, F.; Wanelik, K. (2015). J. Synchrotron Rad. 22(3), 828-838.

Filik, J., Ashton, A.W., Chang, P.C.Y., Chater, P.A., Day, S.J., Drakopoulos, M., Gerring, M.W., Hart, M.L., Magdysyuk, O.V., Michalik, S., Smith, A., Tang, C.C., Terrill, N.J., Wharmby, M.T., Wilhelm, H. (2017). J. Appl. Cryst. 50, 959-966.

Gaisford, S. (2013). Essentials of pharmaceutical preformulation. Chichester, West Sussex, U.K.: Chichester, West Sussex : Wiley-Blackwell.

Hart, M.L., Drakopoulos, M., Reinhard, C., Connolley, Th. (2013). J. Appl. Cryst. 46(5), 1249-1260.

Kato, F., Otsuka, M. \& Matsuda, Y. (2006). Int. J. Pharm. 321, 18-26.

Kawabata, Y., Wada, K., Nakatani, M., Yamada, S. \& Onoue, S. (2011). Int. J. Pharm. 420, 1-10. 
Lee, E. H., Byrn, S. R. \& Carvajal, M. T. (2006). Pharm. Res. 23, 2375-2380.

McConnell, J.F. \& F.Z.Company. (1976). Cryst Struct Comm. 5, 861-864.

McCusker, L., Von Dreele, R., Cox, D., Louër, D. \& Scardi, P. (1999). J. Appl. Crystallogr. 32, 3650 .

Morissette, S. L., Almarsson, O., Peterson, M. L., Remenar, J. F., Read, M. J., Lemmo, A. V., Ellis, S., Cima, M. J. \& Gardner, C. R. (2004). Adv Drug Deliv Rev 56, 275-300.

Otsuka, M. (2004). Solid State Ionics 172, 451-453.

Rietveld, H. M. (1967). Acta Cryst. 22, 151-152.

Rietveld, H. M (1969). J. Appl. Cryst. 2, 65-71.

SeethaLekshmi, S. \& Guru Row, T. N. (2012). Cryst. Growth Des. 12, 4283-4289.

Telford, R., Seaton, C. C., Clout, A., Buanz, A., Gaisford, S., Williams, G. R., Prior, T. J., Okoye, C. H., Munshi, T. \& Scowen, I. J. (2016). Chem. Commun. 52, 12028-12031. 


\section{Supporting Information}

Table S1 Crystallographic data for computationally predicted MA polymorphs, taken from Case et al. 2018.

\begin{tabular}{ccccccc}
\hline Structure ID & M318 & M497 & M664 & M1069 & M1090 & M3912 \\
Space group & $\mathrm{C} 2 / \mathbf{c}$ & $\mathrm{P}-1$ & $\mathrm{Pbca}$ & $\mathrm{Pbca}$ & $\mathrm{Pbca}$ & $\mathrm{P}-1$ \\
$\mathbf{a} / \AA$ & 24.6 & 8.1 & 23.0 & 23.1 & 23.2 & 14.3 \\
$\mathbf{b} / \AA$ & 6.9 & 8.5 & 16.1 & 15.6 & 15.6 & 28.2 \\
$\mathbf{c} / \AA$ & 16.3 & 9.9 & 7.0 & 7.1 & 7.1 & 4.3 \\
$\mathbf{\alpha} /{ }^{\mathbf{0}}$ & 90 & 70.1 & 90 & 90 & 90 & 152.7 \\
$\boldsymbol{\beta} /{ }^{\mathbf{o}}$ & 67.6 & 96.1 & 90 & 90 & 90 & 54.9 \\
$\boldsymbol{\gamma}^{\mathbf{0}}$ & 90 & 82.7 & 90 & 90 & 90 & 125.5 \\
$\begin{array}{c}\text { Cell volume } \\
\left(\AA^{\mathbf{3}}\right)\end{array}$ & 2558 & 627.48 & 2592.1 & 2558.56 & 2569.63 & 639.342 \\
\hline
\end{tabular}

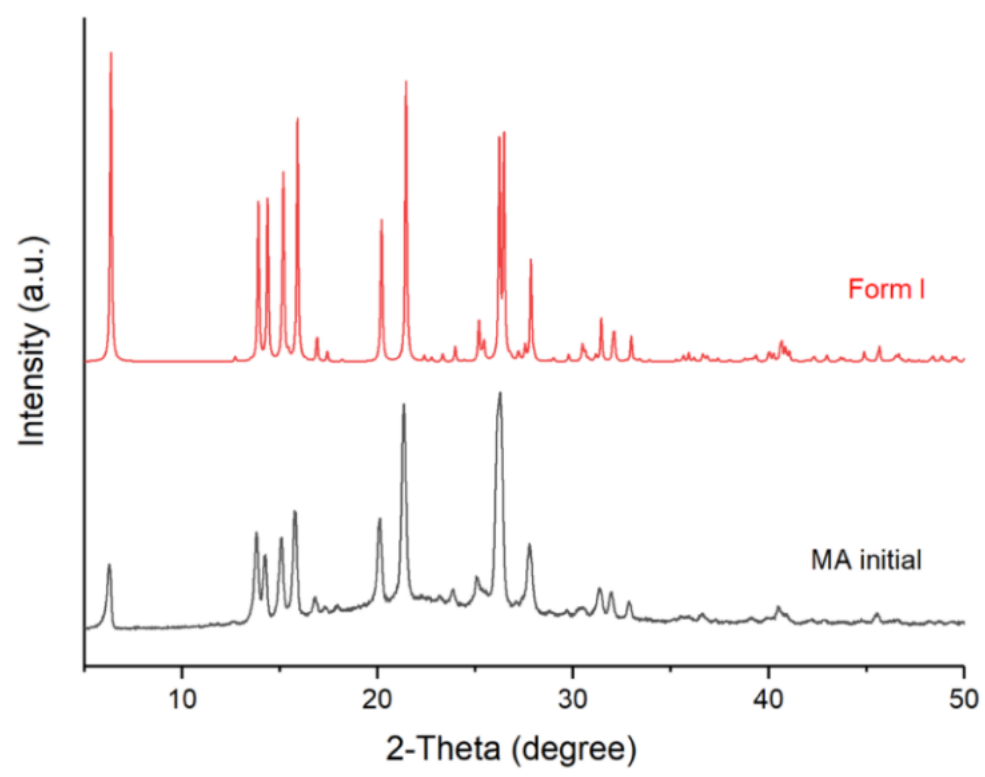

Figure $\mathbf{S 1}$

The XRD patterns of as-supplied MA and that of MA form I (XYANAC) calculated from the CSD (wavelength: $1.5418 \AA$ ). 


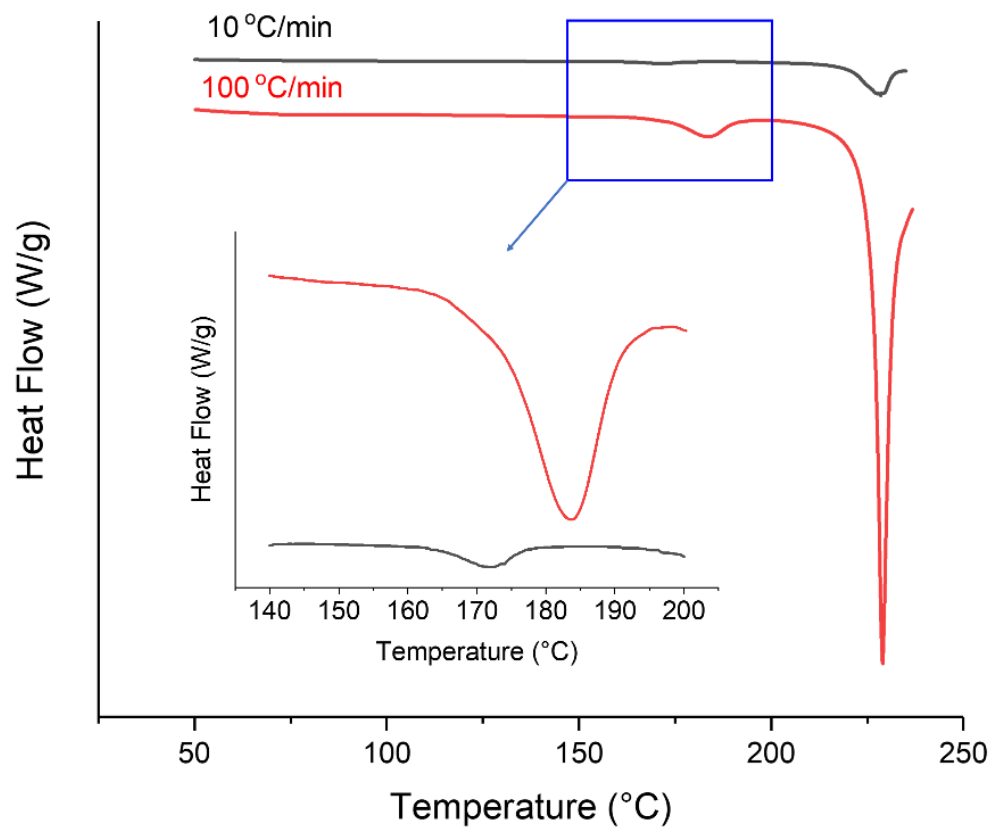

Figure S2

DSC profiles of MA heated from 20 to $230{ }^{\circ} \mathrm{C}$ at 10 and $100{ }^{\circ} \mathrm{C} / \mathrm{min}$. Exo up. 

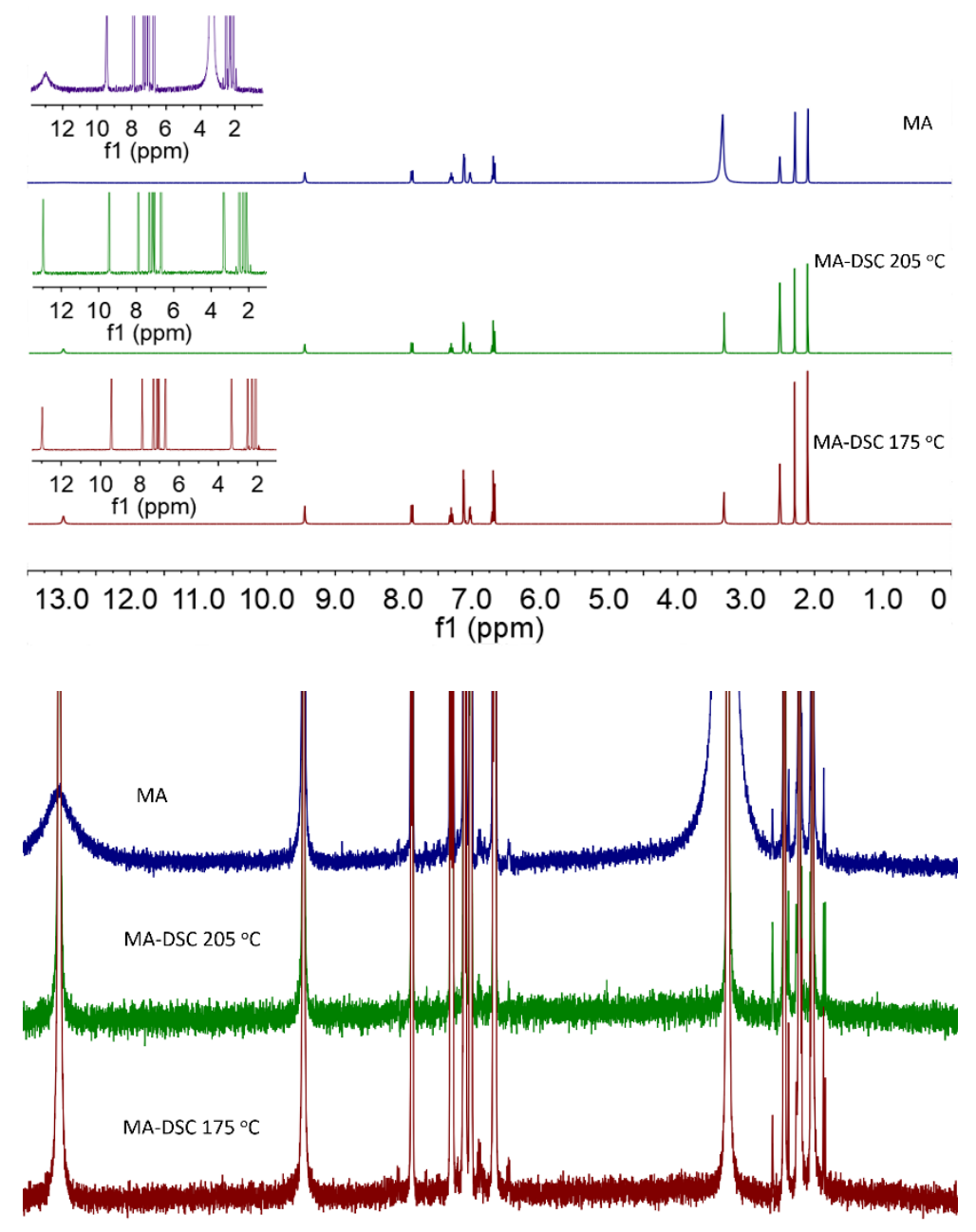

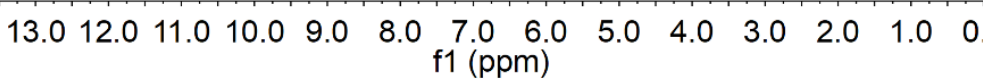

Figure S3

NMR spectra of MA heated to 175 and $205^{\circ} \mathrm{C}$ and that of as-supplied MA. The peak at $13 \mathrm{ppm}$ corresponds to the $\mathrm{MA} \mathrm{COOH}$ group; this is hard to see in the as-supplied MA sample, but can be observed upon enlarging the spectrum. 


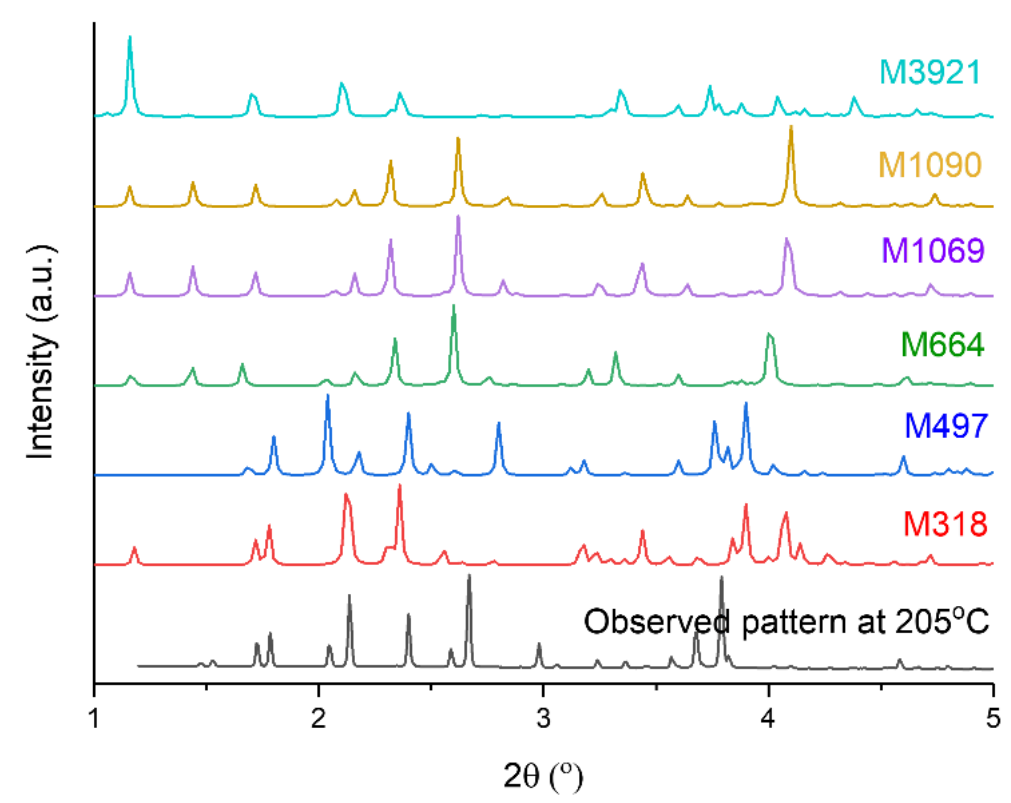

Figure S4

The XRD pattern of MA observed at $205{ }^{\circ} \mathrm{C}$, together with computationally predicted patterns taken from Case et al. 2018 (wavelength: $0.234 \AA$ A). Distinct reflections at 1.47 and $1.53^{\circ}$ cannot be matched with any of form I, II or III; it is clear that none of the predicted patterns fits these either.

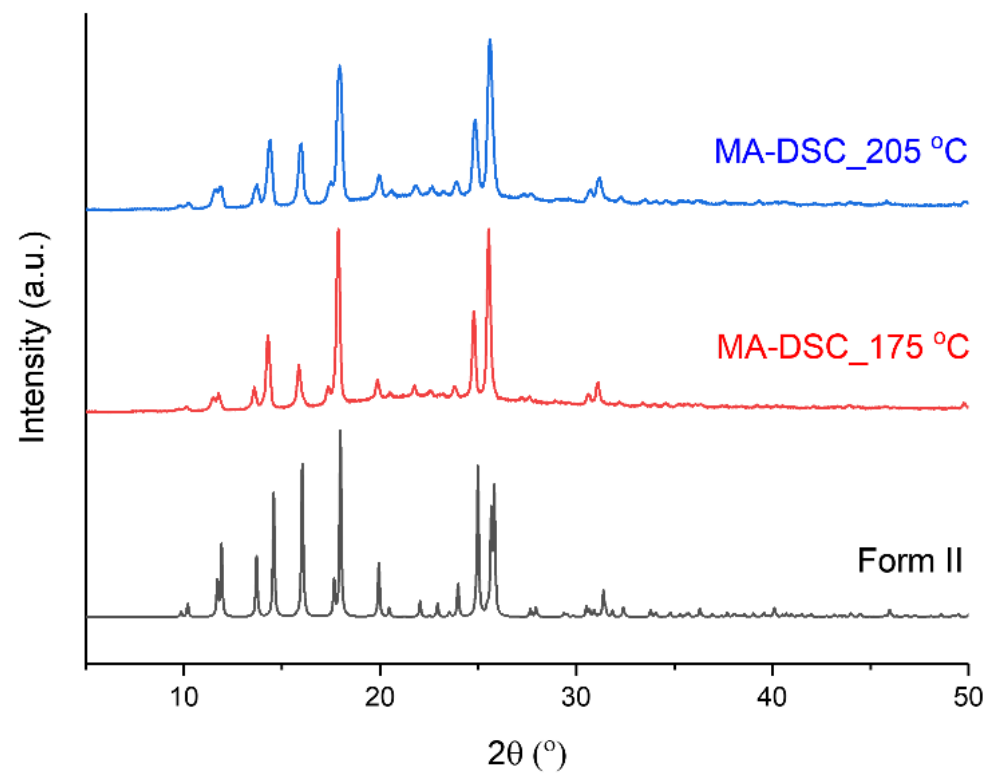

\section{Figure S5}

XRD patterns of MA form II (XYANAC02) calculated from the CSD (wavelength: $1.5418 \AA$ ), together with that of MA heated in DSC to 175 and $205^{\circ} \mathrm{C}$. 